\title{
LADIES IN RED: UMA ANÁLISE DAS MEDIDAS LEGAIS DE COMBATE À VIOLÊNCIA POLÍTICA DE GÊNERO NO BRASIL E EM PORTUGAL
}

\section{Camila Lamartine}

\section{Camila Franco Henriques **}

Resumo

A violência política de gênero é uma realidade que demonstra a insuficiência das ações afirmativas existentes para garantir o exercício pleno dos direitos políticos das mulheres. Assim, este artigo busca investigar de que forma Brasil e Portugal têm atuado legalmente na criação de mecanismos de enfrentamento da violência política de gênero. Foram analisados comentários de leitores nas páginas do Facebook dos jornais Público e Folha de S. Paulo, dirigidos a Dilma Rousseff e a Marisa Matias, enquadrando-os nas seguintes categorias de discriminação de gênero: Cultura Machista, Desqualificante e Ódio. Conclui-se que, apesar dos dados alarmantes de violência política contra mulheres, apenas o Brasil está em processo de discussão de medidas legais para seu enfrentamento.

Palavras-chave: Violência política de gênero, mulheres, Brasil, Portugal, ações afirmativas.

\footnotetext{
Abstract

Ladies in Red: An analysis of legal measures to combat political gender violence in Brazil and Portugal

Political gender violence is a reality that demonstrates the insufficiency of existing affirmative action measures to guarantee the full exercise of women's political rights. Thus, this article seeks to investigate how Brazil and Portugal have acted legally in the creation of mechanisms to face political gender violence. Readers' comments addressed to Dilma Rousseff and Marisa Matias and posted on the Facebook pages of the newspapers Público and Folha de S. Paulo were analysed and sorted into the following categories of gender discrimination: Sexist Culture, Disqualification and Hate. It is concluded that, despite the
}

* $\quad$ Faculdade de Ciências Sociais e Humanas (FCSH)/ Instituto de Comunicação da Nova (ICNOVA), Lisboa, Portugal.

Endereço postal: FCSH/ICNOVA, Avenida de Berna, 26-C, 1069-061 Lisboa, Portugal.

Correio eletrónico: camilalamartinemb@gmail.com

** Faculdade de Direito da Universidade de Lisboa (FDUL), Lisboa, Portugal.

Endereço postal: FDUL, Alameda da Universidade, Cidade Universitária, 1649-014 Lisboa, Portugal.

Correio eletrónico: camilafrancoh@gmail.com 
alarming data on political violence against women, only Brazil is in the process of discussing legal measures to combat it.

Keywords: Political gender violence, women, Brazil, Portugal, affirmative action.

\begin{abstract}
Résumé
Ladies in Red: Une analyse des mesures légales de lutte contre la violence politique de genre au Brésil et au Portugal

La violence politique de genre est une réalité qui démontre l'insuffisance des actions positives existantes pour garantir le plein exercice des droits politiques des femmes. Ainsi, cet article cherche à étudier comment le Brésil et le Portugal ont agi légalement dans la création de mécanismes pour faire face à la violence politique de genre. Les commentaires des lecteurs sur Facebook des journaux Público et Folha de S. Paulo ont été analysés, adressés à Dilma Rousseff et Marisa Matias, en les classant dans les catégories suivantes de discrimination de genre : Culture Machiste, Disqualification et Haine. Il est conclu que, malgré les données alarmantes sur la violence politique à l'égard des femmes, seul le Brésil est en train de discuter des mesures juridiques pour la combattre.
\end{abstract}

Mots-clés: Violence politique de genre, femmes, Brésil, Portugal, actions positives.

\title{
1. Introdução
}

A política é predominantemente masculina desde que foi criada na Grécia, sendo desigual e excludente por origem. Apenas a partir do século XX, passou-se a ter uma progressiva inserção das mulheres na vida política, com a criação de ações afirmativas, como a lei de quotas no Brasil e a lei da paridade em Portugal.

Mas a tomada de espaço político pelas mulheres, muitas vezes, parece uma intromissão. E desta aparente intromissão decorre um ambiente hostil permeado de violência, materializando-se a denominada violência política de gênero, que pode ser vista como mais uma expressão da própria violência de gênero, cujo intuito é apagar e restringir os direitos políticos das mulheres, sendo o gênero o único princípio dessa violência (Albaine 2017).

A violência política de gênero surge de diversas formas. Mulheres são silenciadas, censuradas pelas suas decisões e aparência física, chegando a ser assediadas, violentadas, e até mortas (Instituto Update 2020). Conforme informação apresentada no site do Senado brasileiro (2020), dados levantados pela ONU Mulheres em colaboração com a União Parlamentar Internacional (Inter-Parliamentary Union - IPU) mostram números alarmantes sobre violências sofridas pelas parlamentares: $82 \%$ viveram violência psicológica; $44 \%$ receberam ameaças de morte, estupro, espancamento ou sequestro; $26 \%$ sofreram violência física no parlamento. Dessas, 39\% afirmaram que as condutas impactaram negativamente em seus mandatos e liberdade de expressão. Isto demonstra que as ações afirmativas existentes, em específico as cotas, não são suficientes para assegurar o exercício dos direitos políticos das mulheres. 
Diante deste cenário, e pela necessidade de se pensar em formas de as mulheres exercerem plenamente seus direitos políticos, este estudo parte do questionamento: De que forma Brasil e Portugal têm atuado legalmente na criação de mecanismos para o enfrentamento da violência política de gênero? O seu objetivo geral é analisar a violência política de gênero, retratada pelos casos de Dilma Rousseff e Marisa Matias nas campanhas digitais \#foraDilma e \#vermelhoemBelém, e averiguar como o parlamento dos Estados brasileiro e português têm atuado no seu enfrentamento.

O presente trabalho será, assim, qualitativo e utilizará o método indutivo quanto à abordagem e o comparativo quanto ao procedimento. A pesquisa será feita por meio do levantamento bibliográfico e documental, e a análise será feita através da revisão de literatura.

O artigo se dividirá em três partes. Primeiro discorrerá sobre a evolução da inserção de mulheres na política, dando especial ênfase às leis de cotas e de paridade. Seguidamente, demonstrará a violência política de gênero, a partir dos casos de Dilma Rousseff e Marisa Matias, pela análise dos comentários no Facebook das notícias «Cunha manda e governo Temer terá que se ajoelhar, diz Dilma» do jornal Folha de S. Paulo, no Brasil, e «Insulto não diz nada sobre as mulheres, mas tudo sobre Ventura, defende Marisa Matias» do jornal Público, em Portugal. Por fim, investigará quais as medidas que Brasil e Portugal têm tomado para o enfrentamento da violência política de gênero.

\section{A participação das mulheres na política}

A política é uma forma de atuação social excludente por origem. Criada na Grécia, ela surge da criação da polis, constituinte do espaço público, frequentado apenas por homens. Enquanto isso, as mulheres eram limitadas às tarefas domésticas, no âmbito do oikos (Tiburi 2019). A polis era considerada um fim em si mesma, enquanto o oikos tinha a função de dar condições para que a vida pública se concretizasse (Azevedo 2019). Essa situação se manteve por milênios.

Foi o movimento feminista que possibilitou a entrada das mulheres no contexto político, em princípio com o sufragismo eclodido no Reino Unido (Saffioti 2013). Esses movimentos garantiram uma série de avanços na luta feminina por reconhecimento a nível de direitos humanos (Pinto 2010).

Nesta senda, discorrer-se-á, brevemente, sobre a evolução da relação entre as mulheres e a política no Brasil e em Portugal, em dois momentos: primeiro, com uma resenha histórica da inserção política das mulheres portuguesas e brasileiras e, depois, com a análise da Lei de Cotas no Brasil e da Lei da Paridade em Portugal. 


\subsection{A inserção das mulheres na política portuguesa e brasileira}

Inserida no momento de eclosão do movimento sufragista, Carolina Beatriz Ângelo foi a primeira mulher a votar em Portugal (Lousada [2011], 4). Conforme a regulamentação eleitoral existente até a eleição da Assembleia Constituinte em maio de 1911, podiam votar todos os portugueses, maiores de 21 anos, residentes no território nacional, que soubessem ler e escrever e fossem chefes de família, dando sustento à mesma (Portugal 1911). Diante desta disposição, Carolina Beatriz Ângelo, com 33 anos, viúva, mãe de uma menina de 8 anos, médica praticante e com rendimento próprio, entrou com um pedido judicial de autorização para exercer o direito de sufrágio (Lousada [2011], 2) e consagrou-se na história portuguesa ao votar para a Assembleia Constituinte de 1911.

Para que o movimento das sufragistas não ganhasse força e se beneficiasse da abertura na legislação eleitoral, em julho de 1913 o Código Eleitoral foi alterado ${ }^{1}$, permitindo o voto a todo o cidadão português do sexo masculino, maior de 21 anos e que soubesse ler e escrever (Portugal 2013), vedando expressamente a participação feminina. Verifica-se, assim, a insistência na exclusão de mulheres do espaço político.

As mulheres só adquiriram direito a votar e serem votadas durante o Estado Novo. Maria Baptista Guardiola, Maria Domitília de Carvalho e Maria Cândida Parreira foram as primeiras mulheres eleitas deputadas. No entanto, estas mulheres não representavam a mulher portuguesa comum - analfabeta quando não era da elite, e quando era, educada até ao primeiro grau. Apesar de eleitas, não atuaram em presidências ou secretarias na Assembleia Nacional e reforçaram, por meio de seus discursos, a ideologia governamental baseada na tríade Deus-PátriaFamília, defendendo o papel das mulheres como serventes, submissas e mães (Adão e Remédios 2005, 85), sugerindo que o espaço a elas ofertado fortalecia o sistema de dominação e exclusão imposto.

No Brasil, Isabel de Mattos Dillon, em 1885, invocou a Lei Saraiva, por possuir o título de dentista, e pediu o alistamento eleitoral. O juiz de primeira instância indeferiu, alegando que a provisão eleitoral não incluía a qualificação de mulheres (A Federação 1886). Isabel recorreu e ganhou em segunda instância, mas não teve sua inscrição reconhecida no alistamento eleitoral pela mesma justificativa do juiz de primeira instância (Ministério do Interior 1889): era mulher. Décadas depois, em 1928, Celina Guimarães Viana, professora, se torna a primeira mulher a votar no Brasil diante da Lei estadual 600/1927, que estabelecia a extinção da distinção por sexo no Estado do Rio Grande do Norte.

Carlota Pereira de Queiroz foi a primeira mulher eleita deputada federal, em 1933, enquanto no Senado as primeiras representantes mulheres, Júnia Marise e

Disponível em https://purl.pt/5854/1/documentos/Legislacao\%20Eleitoral\%20-\%20REPU BLICA.pdf [Consultado a 23 de junho de 2021]. 
Marluce Pinto, só foram eleitas em 1990. Em 2011, mulheres ocuparam a mesa da presidência do Congresso Nacional, sendo Rose de Freitas vice-presidente da Câmara dos Deputados e Marta Suplicy vice-presidente do Senado.

O cargo mais alto do executivo foi exercido somente por uma mulher, Dilma Rousseff, a única presidente mulher do Brasil até o momento. Dilma sofreu impeachment na metade do seu segundo mandato, tendo exercido a presidência por 6 anos.

Mesmo com a possibilidade legal de participação de mulheres na vida política, independentemente de posicionamentos ideológicos, entre 1935 e 1974 em Portugal, não havia mulheres em cargos governamentais e seu percentual na Assembleia Nacional foi, em média, 2\% (Adão e Remédios 2005, 87). A participação de mulheres no governo «[...] entre 1976 e 1995 limitou-se a seis Ministras, 33 Secretárias de Estado e quatro Subsecretárias de Estado, o que representa 5,8\% do total dos membros dos governos deste período» (Almeida 2015, 167). Já o mais alto cargo de governação em Portugal foi desempenhado por uma mulher somente em 1979. Maria de Lurdes Pintasilgo foi nomeada Primeira-Ministra, exercendo um mandato curto de apenas cinco meses (Almeida 2015). Atualmente, as mulheres representam 39\% do parlamento (Lusa 2021).

No Brasil atual, as mulheres representam 9,94\% do total de deputados federais e $16 \%$ dos senadores, mesmo sendo mais da metade da população, sendo um dos países com menor representatividade feminina no Congresso Nacional (Toledo e Jardim 2019).

Percebe-se, assim, que há uma progressiva inserção das mulheres na vida política, tanto em Portugal, quanto no Brasil, e isso decorreu, também, diante da adoção de ações afirmativas para impulsionar a participação política feminina.

\subsection{Espaço para elas: a Lei de Cotas no Brasil e a Lei da Paridade em Portugal}

Acompanhando uma mudança global fomentada por movimentos sociais e feministas, Portugal e Brasil adotaram o sistema de paridade e de cotas, respetivamente, como uma via mais célere para o enfrentamento da desigualdade de gênero na política (Santos e Espírito-Santo 2017).

Em Portugal, as mulheres conseguiram um maior avanço legislativo a partir da implementação da Lei da Paridade no ano de 2009. Atualmente, a lei estipula que haja um mínimo de $40 \%$ de mulheres nas listas eleitorais para a Assembleia da República, autarquias e Parlamento Europeu, e impõe aos partidos a alternância de sexos nas listas, ou seja, não se pode registar duas pessoas do mesmo sexo de forma consecutiva.

Com a Lei da Paridade houve uma maior inserção política de mulheres, ainda que elas se enquadrem como minoria na maior parte dos cargos de poder e gestão (Almeida 2015, 172). Neste quesito, importa destacar que, apesar do uso do termo «paridade», houve, na realidade, a instituição de um limiar mínimo de paridade 
com o número de mulheres suficiente para compor uma massa crítica política, ou seja, um número suficiente para possibilitar mudanças (Santos e Espírito-Santo 2017, 19).

No Brasil, ações afirmativas para inclusão de mulheres na política começaram com a Lei 9.100/1995, que estipulava o mínimo de $20 \%$ das candidaturas de cada partido ou coligação para mulheres. Dois anos depois, com a Lei 9.504/1997, foi regulado o mínimo de $30 \%$ e máximo de $70 \%$ das candidaturas para cada sexo. A alteração na lei das eleições pela lei 12.034/2009 substituiu o termo «reservar» por «preencher» no parágrafo $3 .^{\circ}$ do artigo 10 , no que diz respeito ao percentual mínimo e máximo para cada sexo.

Apesar da adoção da Lei da Paridade e da Lei de Cotas, ainda falta muito para a conquista da igualdade no sistema político, considerando que somente duas mulheres, em ambos os países aqui analisados, conseguiram ser eleitas para o cargo mais alto de comando, com a ressalva de que, em Portugal, nenhuma mulher ainda foi eleita Presidente da República. Além disso, verificou-se, no tópico anterior, que a representação das mulheres em cargos políticos e governamentais ainda está muito aquém da real representação da população (Senado Federal 2020).

A violência contra as mulheres na política é uma das formas de afastá-las desses espaços (Lunz 2021), além de outros aspectos que não serão aqui analisados, mas que devem ser, ao menos, citados, como a incipiente socialização das mulheres na política, a discriminação dentro dos próprios partidos e a falta de tempo e energia pela desigual divisão sexual do trabalho (Ferreira 1999; Almeida 2015; Santos e Espírito-Santo 2017; Lunz 2021).

A sub-representação feminina na política é um reflexo da construção social baseada no patriarcado, onde o silenciamento é o grande precursor da violência, que atinge domínios psicológicos e físicos (Biroli 2010). Práticas visíveis e invisíveis precisam ser denunciadas, mas para que isso ocorra, é necessário que se conheça e reconheça como a violência política de gênero se materializa, o que será feito a seguir.

\section{Violência política de gênero}

Antes de adentrar no componente gênero, é importante entendermos de que trata a violência política, especificamente, considerando que a violência, por si só, funciona como uma ferramenta elementar da política constituindo-se como fenômeno instrumental, uma vez que exercer política se relaciona ao exercício do poder, da centralização das relações de poder e do uso da força, ainda que de forma organizada e legítima (Lauris e Hashizume 2020, 8).

Lauris e Hashizume $(2020,11)$ sugerem quatro formas distintas de atividade pela qual a violência política se concretiza. Inicialmente, manifesta-se a partir de atos físicos, simbólicos ou de intencional desestabilização psicológica. Em segundo 
lugar, realiza-se por ações coletivas ou individuais, mas de maneira isolada, difusa ou organizada. Depois, há a inserção de uma maior demonstração de força física e de intimidação emocional ou psicológica. Por fim, apresenta os danos causados pelos adversários diretos, sejam pessoas físicas ou jurídicas.

Uma das ramificações dessa violência é a de gênero, exercida diretamente contra as mulheres, cujo mote é unicamente o componente de gênero. Ou seja, se dirige às mulheres somente porque elas são mulheres (Albaine 2017). Parece fácil identificar esse tipo de violência; no entanto, como elucida o Instituto Update $(2020,53)$, quando o gênero é fator basilar, ela está tão enraizada e entranhada na sociedade que acaba sendo naturalizada.

Impedir mulheres de exercerem o seu direito político de votar e serem votadas por meio de agressões psicológicas, sexuais ou físicas tem nome: violência política de gênero. E deve desfazer-se uma confusão comum: violência de gênero não é apenas um ataque a alguém de um gênero específico, mas sim um ataque motivado pelas expectativas sobre o papel que a vítima deveria desempenhar na sociedade. Em geral, no caso da violência contra as mulheres, seus algozes acreditam que ela não deveria ocupar outro lugar que não o da submissão (Instituto Update 2020, 52).

Como elucida Pinho (2020, 3), a América Latina tem sido ferrenha crítica neste assunto, tendo a Bolívia sido pioneira ao tipificar a violência política contra as mulheres em 2012. No México, houve a implementação da Lei sobre o Acesso das Mulheres a uma Vida Livre de Violência e do Código Federal Eleitoral em 2013.

Dessa forma, o Instituto Update define a violência política de gênero como todas as ações ou omissões, de forma direta ou indireta, que objetivam menosprezar ou anular o reconhecimento dessas mulheres, o exercício e o usufruto dos direitos e prerrogativas de um cargo público. Além disso, também é enquadrada a prática de desestímulo e limitação de mandatos femininos (Instituto Update 2020, 52).

O relatório Violência Política e Eleitoral no Brasil (Lauris e Hashizume 2020) demonstra que a experiência dos homens e mulheres em relação aos casos de violência política são drasticamente divergentes. Todavia, a constante vitimização da mulher deve ser sobreposta ao fato da ocupação de cargos políticos por elas ser menor.

Também se percebe que os maiores ataques ao sexo feminino na política dizem respeito aos abusos psicológicos, assédios e intimidações: «Trata-se de situações sistemáticas de assédio ao trabalho de determinadas/os políticas/os de grupos partidários minoritários via procedimentos, obstruções, denegação de pedidos, omissões propositais e outros tipos de estratégias de bloqueio» (Lauris e Hashizume 2020, 70).

Isto é ainda mais agravado e intensificado devido à Internet, que atua como um grande espaço fomentador da disseminação de campanhas de desinformação e fake newss, pois permite que a não identificação do propagador (pelo menos não fisicamente) seja gatilho de liberdade condicional (Recuero 2014). Como corrobora 
Jenkins $(2009,7)$, a Internet desenvolve-se como um espaço público idealmente democrático, que permite a participação popular e formas inovadoras de envolvimento cívico e meios de (re)construção da opinião pública.

Essa violência direcionada às mulheres na política tem o poder sexista de ir mais além do ato em si. Serve, em certa parte, como uma ferramenta de desencorajamento, através do exemplo para os outros milhares de mulheres que tencionam adentrar no sistema político, como se o poder da tomada de decisão e governação da sociedade não fosse campo ou espaço para mulheres, voltando a premissa dicotômica do público e do privado. «Para além da forma e do objetivo, a violência política de gênero se diferencia dos ataques violentos cometidos por oponentes em meio ao embate político, em função de sua origem mais difusa» (Pinho 2020, 5).

A violência política de gênero permanece naturalizada, não vindo a ser nem ao menos reconhecida e tipificada na legislação vigente em Portugal e no Brasil. E, para demonstrar casos emblemáticos dessas questões, parte-se para a análise dos casos de Dilma Rousseff e Marisa Matias.

\section{Ladies in red: violência nos casos de Dilma Rousseff e Marisa Matias}

O vermelho é a cor mais antiga de denominação cromática do mundo e, portanto, é simbólica de todas as atitudes positivas em relação à vida. É a cor que traduz força, vida, coragem, mas também a cor da agressividade e excitação (Heller 2014, 55). Não é à toa que foi a cor escolhida por Marisa Matias e Dilma Rousseff para suas campanhas. Além de ser a cor utilizada pelos seus partidos, Bloco de Esquerda e Partido dos Trabalhadores respetivamente, é através do vermelho que intencionou-se transmitir a energia vibrante dessas políticas.

Apesar de estarem em contextos sociopolíticos diferentes, inclusive em termos de temporalidade, os casos demonstram e representam a violência política de gênero exercida sobre as mulheres políticas, pois, como visto, a violência política de gênero pode se revelar em diversos formatos, não sendo as agressões físicas as únicas a serem contempladas (Albuquerque e Alves 2018). Essa violência pode ser exercida por inúmeros agentes a começar pelo Estado, e incluindo também os partidos políticos, a mídia e até mesmo os usuários das redes sociais digitais (Albaine 2017).

Pandora Penaforte (2017), que faz um minucioso estudo acerca da contribuição dos comentários anónimos na construção da opinião pública, explicita que, particularmente, os comentários dos jornais online apresentam um teor linguístico mais ofensivo, onde os usuários verbalizam conteúdos que são prejudiciais. Para a autora, esses comentários traduzem uma total inexistência de literacia que seja capaz de pensar e fomentar um espaço público que seja de fato democrático, o que identifica, ainda, a ausência de uma democracia deliberativa. 
Esses comentários conseguem traduzir a opinião dos usuários principais do jornal e a sua participação, como no caso de um dos jornais aqui analisados, o Público que, através das caixas abertas para comentários, pretende perceber e conhecer instantaneamente a opinião dos leitores em relação a assuntos específicos (Ribeiro 2013), incluindo os que são mais complexos e delicados.

Assim, optou-se por analisar os comentários efetuados pelos leitores em duas postagens dos perfis no Facebook de grandes jornais em cada país, sendo no Brasil a Folha de São Paulo, com 5.503.455 seguidores, e o jornal Público em Portugal, com 1.184.768 seguidores. A escolha da plataforma se deu devido ao seu alcance mundial, sendo líder absoluto em número de usuários de acordo com dados do portal Statista ${ }^{2}$, sendo a primeira a superar a marca de 1 bilhão de utilizadores, somando na atualidade 2,701 bilhões de usuários ativos, além de ser bastante utilizada pela mídia como catalisador de opinião dos seus utilizadores.

Para definir as postagens analisadas, utilizou-se a ferramenta pesquisar em ambos os perfis, introduzindo o nome das mulheres políticas Dilma Rousseff (BR) e Marisa Matias (PT). Dentre as postagens filtradas, optou-se por selecionar as que vieram após ações diretas de violência política de gênero.

No caso de Dilma Rousseff, a análise se debruçou na publicação do dia 28 de maio de 2016 - três meses antes de ser destituída do cargo de presidenta - na página do Facebook da Folha de São Paulo. Intitulada «Cunha manda e governo Temer terá que se ajoelhar, diz Dilma» ${ }^{3}$, contabiliza 3,8 mil curtidas/gostos e 837 comentários.

No caso de Marisa Matias, a postagem é referente ao discurso de Matias após o ocorrido durante comício em Portalegre, que originou a campanha online \#vermelhoemBelem. A publicação do dia 15 de janeiro de 2021 no perfil do Facebook do Público «Insulto não diz nada sobre as mulheres, mas tudo sobre Ventura, defende Marisa Matias» ${ }^{4}$ computa 3,4 mil curtidas / gostos e 305 comentários.

Dos comentários contidos nas postagens, foram esmiuçados 50 no de Dilma Rousseff e 31 no de Marisa Matias, que continham algum tipo de insulto e/ou ofensa direcionados a elas e não se repetiam, apresentando uma linguagem imprópria, falta de respeito pela diversidade e um intuito de minorar e rebaixar descaracterizando o que seria democracia deliberativa (Penaforte 2017, 10). Destes, importa relevar que sua maioria foi proferida por pessoas do sexo masculino. $\mathrm{Na}$ matéria da Folha de São Paulo registou-se 62\% de comentários masculinos para 38\% de femininos, enquanto a do Público apresentou $88,5 \%$ para $11,5 \%$.

2

https:/ / www.statista.com/ statistics / 272014/ global-social-networks-ranked-by-numberof-users / [Consultado a 20 de maio de 2021].

3 https: / / www.facebook.com/folhadesp/posts/1364452010263465 [Consultado a 15 de maio de 2021].

4 https://www.facebook.com/Publico/posts/10159211612026983 [Consultado a 15 de maio de 2021]. 
A fim de melhor perceber as tipologias da natureza ofensiva dos comentários, os dados foram divididos em três grandes categorias. A primeira, intitulada "Cultura Machista», inclui insultos relacionados à questão do papel social da mulher, bem como seus aspetos físicos e estéticos no tocante a um padrão de beleza utópico e subjetivamente definido. O outro núcleo de análise é o «Desqualificante», onde são alocados os comentários que fazem referência ao mansplaining, coação psicológica e desmerecimento da função ou papel desenvolvido referente ao cargo. Por fim, a terceira categoria intitula-se "Ódio», agregando todos os discursos de ódio, com caráter de violência e ainda de misoginia.

Vale ressaltar que os comentários transcritos permaneceram fiéis ao original, não sendo corrigidas pelas autoras gralhas ou faltas de pontuação.

\subsection{Cultura machista}

A cultura machista está enraizada na sociedade, pois, como refere Akotirene (2019), existem discursos proferidos pelo sexo masculino que são produzidos diretamente pela ordem patriarcal e são, por fim, os grandes responsáveis no que tange à criação de modelos subjetivos do ser feminino. Dessa forma, as mulheres são estigmatizadas como uma categoria pertencente ao outro, ao pai, ao irmão, ao marido, e acabam obrigadas a obedecer, transformando-se, também, em cúmplices da própria violência com que são deparadas cotidianamente.

Neste tópico os comentários revelam uma atenção particular em relação à imagem, até à própria alocução proferida por André Ventura, durante o comício onde questionou o uso do batom vermelho de Matias, considerando-o inadequado: «Não está muito bem em termos de imagem e performance, assim com os lábios muito vermelhos como se fosse uma coisa de brincar». Esta fala compreende um discurso machista, sexista quando enquadra a mulher como «coisa de brincar», sendo uma clara e direta violência política de gênero, pois como referem Lauris e Hashizume (2020), a intimidação psicológica e discriminatória com o agravante de conteúdo de teor ofensivo visa desestabilizar a participação política. Assim, Ventura profere este comentário dirigido a sua adversária a fim de estremecer sua candidatura e desestruturá-la.

ComM.1: Eu acho que uma sombra nos olhos e um rímel lhe ficavam melhor que o batom! COMM.2: CÁ PARA MIM A MARISA E A ANA GOMES TEM UM FRAQUINHO PELO VENTURA!

ComD.1: Ajoelhar? Será ela quando as investigações terminarem pena que vai ser prisão domiciliar, cheia de regalias podia ser em um presídio feminino normal. Ela poderia liberar os instintos sexuais a vontade]

ComM.3: Quais mulheres???? Não se sabe se ela é macho ou fêmea $\hat{Q} \hat{Q} \hat{Q} \hat{n} \hat{n} \hat{Q} \hat{Q} \hat{Q} \hat{Q}$ ComM.5: Anda a comer muito! Será chocolate?? 
ComD.2: Eu não entendo porque esta mulher não vai cuidar dos netos, em vez de continuar falando besteira

ComD.4: A mulher Sapiens !

Estes comentários fazem alusão ao papel social imputado às mulheres, o que, como explicam Dantas e Rubim (2018, 21), comprova a inexpressiva presença feminina nos editoriais políticos, cujo enquadramento se baseia em estereótipos de gênero com expressivo destaque às questões familiares e estéticas quando se fala de uma mulher num posto político.

\subsection{Desqualificante}

O grupo Desqualificante apresentou-se como o mais expressivo, enquadrando-se nele todos os comentários que duvidassem da capacidade das políticas, as descredibilizassem e colocassem num papel de vitimização constante, tão bem utilizado e retratado pela mídia.

Percebe-se uma necessidade masculina em demonstrar conhecimento superior, desqualificando o discurso das mulheres, em especial seu intelecto, e explicando o óbvio. Isso pode-se denominar de mansplaining 5 , um termo cunhado pela escritora Rebecca Solnit no livro Os homens explicam tudo para mim (2017), onde ela tece uma ferrenha crítica acerca da ideia de que, por serem mulheres, elas não saberiam de assuntos além daqueles relativos ao desempenho dos seus papéis sociais tradicionais, não sendo capazes de exercer o cargo. Isto acontece na medida em que um homem minora o conhecimento de uma mulher e tenta explicar em seu lugar a premissa de que ela, por ser mulher, não seria capaz de perceber a temática (Liguori 2015).

ComM.15: Mulher mal consigo própria e com a vida, é um problema que dispara para todas as direções. Calhou te a ti André, que não lhe deste colinho.

ComM.21: Esta Marisa é muito fraca, coitada!

ComM.24: É sempre bom haver um palhaço, para animar as hostes

ComM.25: Está na moda a teoria do coitadinho e das vítimas com telhados de vidro.

ComD.07: e uma mentirosa patológica!

ComD.16: Hahahahaha, Dilma sempre falou asneiras enquanto estava no poder, será que o afastamento a fez deixar de praticar as asneiras?

ComD.24: É tão incompetentA, que sequer soube escolher seus pares.

ComD.25: Louca, apenas isso

Como explicam Dantas e Rubim $(2018,8)$, os estereótipos mais comuns tornam-se espontaneamente identificados e acessíveis em todos os lados, sobretudo na mídia,

O termo mansplaining é resultado da fusão entre man (homem em inglês) e explain (verbo explicar em inglês), que seria em tradução «homens a explicar». 
enfatizando que esta narrativa ultrapassa a questão estética, que serve como avaliação de desempenho onde as características femininas tornam-se basilares. Portanto, é notória a associação entre desempenho e gênero neste tipo de função.

Nesta categoria, especificamente no caso de Dilma Rousseff, é importante ressaltar a prática do bropriating, muito comum em diversos comentários analisados. O bropriating também parte da união de duas palavras, a abreviação bro (de irmão em inglês) e appropiating (apropriação em inglês), que resultaria em «homens que se apropriam». Esta ação acontece quando um homem toma a ideia de uma mulher recebendo o bônus em seu lugar, a invisibilizando a partir da apropriação (Liguori 2015).

ComD.20: Pois é.... língua é o chicote...no desgoverno dela o Lula mandava, pintava, bordava, e deitava e rolava

ComD.21: Que moral essa mulher tem? Tem quem por tras ne?!

Na análise dos comentários a Dilma Rousseff, é notório o apagamento da sua desenvoltura enquanto presidente na perspetiva de que todos os seus atos de governo foram manipulados por um homem que seria seu mentor, uma vez que esta não teria capacidade para fazer tal trabalho sozinha. Para Liguori (2015) isto pode ser considerado como uma surdez seletiva que se relaciona diretamente ao gênero, onde se nega que as mulheres sejam protagonistas das suas próprias histórias.

\section{3. Ódio}

A categoria Ódio apresentou uma certa discrepância em relação às publicações analisadas, sendo a brasileira bem maior em número de comentários. No entanto, os comentários tiveram aqui um teor de violência física aprofundado com misoginia. É claramente perceptível nas entrelinhas a repulsa contida através de verdadeiros discursos de ódio e conteúdo demasiadamente ofensivo.

ComM.27: Cabra filha dum gatuno que te formatou para seres mais uma

ComM.29: Eu gostava muito de insultar esta senhora e chamar-lhe vários nomes

ComM.30: Não vales nada. Nem como mulher, nem como política.

ComD.40: Essa barra de gelo ainda ta falando?? Alguém enfia uma mandioca bem grande na boca dela pelo amor de Deus??

ComD.41: A Rainha do NADA está cada dia mais louca... a entrevada acabará no manicômio judiciário até o fim de suas penas federais

ComD.48: VAI ATÉ PRO INFERNO.

ComD.49: Continua exumando a defunta

ComD.50: VAI pro inferno que é seu lugar cão 
Isto é explicado por Recuero (2014) na medida em que o ciberespaço permite que a máscara do ecrã deixe de lado a interação presencial, tornando livre o usuário para expor seus pensamentos devido ao distanciamento físico.

É esta liberdade implícita da cibercultura que serve como espaço para a emergência de discursos de caráter agressivo, ofensivo, hostilizado e propagador de violência devido a uma errónea postura dos leitores (e cidadãos) no que diz respeito à construção verbal e opiniões desestimulantes embasadas, na maioria das vezes, em motivações partidárias (Ribeiro 2013, 437).

\section{Medidas governamentais para o enfrentamento da violência política de gênero em Portugal e Brasil}

Como demonstrado, a socialização feminina somada à violência política de gênero limita e afasta esse grupo da vida política. Dessa forma, para que haja uma maior participação das mulheres na vida política é necessária a implementação de políticas públicas que atuem no favorecimento da igualdade de gênero garantindo meios emancipatórios a elas. Essas medidas dão oportunidade para que exista um desenvolvimento prático das garantias políticas e civis já conquistadas no papel, ainda que se viva numa sociedade que as discrimina e hostiliza, uma vez que tem por base o patriarcado (Pinto 2010).

Neste sentido, percebeu-se pelos dados apresentados que a participação das mulheres na vida política ainda está aquém do que representaria a quantidade das mulheres nas respetivas populações, mesmo que já tenham passados mais de 10 anos da implementação das ações afirmativas pensadas para incluí-las. Verificou-se, também, que a violência política de gênero é um dos fatos que afasta mulheres da vida política, mas que permanece sem legislação para sua repressão. Assim, importa que sejam pensadas novas medidas para o exercício pleno dos direitos políticos das mulheres.

Na América Latina, após a implementação na Bolívia, em 2012, este tema entrou na pauta legislativa no Equador, Costa Rica, México e Peru, mas não foi, ainda, aprovado. Contudo, países como Equador e Peru têm regulamentações sobre assédio político (Pinho 2020, 3), que têm como foco o combate à violência política de gênero, mesmo sem usar o termo.

No Brasil, em 2020, a Câmara dos Deputados aprovou um Projeto de Lei para o combate da violência política contra as mulheres. O Projeto de Lei 349/15 foi proposto pela deputada Rosângela Gomes e aprovado. Conceitua violência política contra as mulheres, no Art. $3^{\circ}$, como «[...] toda ação, conduta ou omissão com a finalidade de impedir, obstaculizar ou restringir os direitos políticos da mulher».

Na função de relatora, a deputada Ângela Amin reforça a importância da regulamentação e explica que, antes da Lei Maria da Penha, a violência doméstica era naturalizada, bem como a violência política de gênero ainda é. Relembrou que, 
nas últimas eleições, muitas mulheres sofreram ataques misóginos e que a Internet tem sido um meio de intensa veiculação desse tipo de violência. Pertinente se faz o cuidado de tratar, além de questões de gênero, questões de cor, raça ou etnia para proteção de candidatas e mandatárias (Amin 2020). O projeto ainda aguarda análise no Senado.

Enquanto o Brasil mostra ao menos um princípio de discussão legislativa sobre o tema, em Portugal não foram encontrados debates para proposições de ações afirmativas para o enfrentamento da violência política de gênero no âmbito legislativo.

\section{Considerações finais}

Como exposto, as mulheres, progressivamente, inserem-se na vida política, havendo um aumento percentual relevante nas últimas décadas, em especial com as ações afirmativas já existentes (Lei da Paridade e Lei de Cotas). Todavia, sua participação ainda está aquém do que se espera numa representação real e igualitária da sociedade.

É curioso observar que, em quase 80 anos de vida política das mulheres, tanto no Brasil quanto em Portugal, apenas uma mulher ocupou o cargo mais alto na chefia do Estado, ainda que em terras lusitanas nenhuma mulher tenha sido Presidente. Isto reforça a hipótese da insuficiência de ações afirmativas que fomentem a participação política das mulheres.

Relacionada à inserção política feminina, a violência política de gênero acaba por afastar as mulheres da vida política, sendo que a grande maioria dos casos se realiza através de ameaças, intimidações, ofensas e humilhações. É crucial identificar essas violências para desnaturalizá-las.

Nos casos de Dilma Rousseff e Marisa Matias, a violência política de gênero foi demonstrada, não só através dos comentários dos leitores no ciberespaço, como também nos discursos que precederam tais campanhas digitais. São ataques de ódio que devem ser melhor analisados em relação à mídia, aos jornalistas e demais formadores de opinião.

Em resposta à questão de investigação deste artigo, revela-se que apenas o Brasil possui uma discussão em andamento no Parlamento sobre a criação de mecanismos legais para o enfrentamento desta violência. Apesar disso, Portugal se mostra à frente quanto à percentagem de participação feminina no Parlamento, com 39\%, enquanto no Brasil é de 9,94\% na Câmara dos Deputados e 16\% no Senado. Talvez, por isso, sinta-se mais necessidade desse debate no Brasil neste momento, reforçando a hipótese de que a violência política de gênero, dentre outros fatores, afasta as mulheres da vida política.

Contudo, provou-se que a violência política de gênero é realidade em ambos os países e a crescente participação das mulheres nesse espaço público não implica a extinção deste tipo de conduta. Pelo que se reforça a necessidade de uma maior 
investigação e um olhar mais atento em relação aos casos desse tipo de violência e à desnaturalização do papel social das mulheres. Especialmente porque é imperiosa a maior participação de mulheres nos espaços políticos, tendo em vista que elas são os melhores indivíduos para representar as demandas femininas. Tanto assim é que a proposição do Projeto de Lei, quanto à escolha das relatoras, foi feita por deputadas federais.

Neste período pandémico, em que o isolamento social deixa clara a centralidade do papel da mulher no seio familiar e no que tange à própria organização da sociedade (Instituto Update 2020), percebe-se a necessidade de avançar numa democracia mais igualitária com livre participação feminina no exercício de seus direitos políticos e nas tomadas de decisões, não só no âmbito privado, como sempre lhes foi atribuído, mas, especialmente, no âmbito público, para que haja uma efetiva possibilidade de representação e de transformação social.

\section{Referências bibliográficas}

Adão, Áurea, Maria José Remédios. 2005. «A narratividade educativa na $1^{\text {a }}$ fase da governação de Oliveira Salazar. A voz das mulheres na Assembleia Nacional portuguesa (1935-1945).» Revista Lusófona de Educação 5(5): 85-109.

Akotirene, Carla. 2019. O que é interseccionalidade? São Paulo: Pólen.

Albaine, Laura. 2017. "Contra la violencia política de género en América Latina: Las oportunidades de acción.» Comunicação apresentada ao $9^{\circ}$ Congresso Latino Americano de Ciência Política, 26-28 de julho, Montevideu, Uruguai.

Albuquerque, Juliene, Elba Alves. 2018. «Apontamentos sobre a violência contra a mulher na política institucional brasileira.» Revista Debates Insubmissos 1(2): 143-163. DOI: https:/ / doi.org/10.32359/ debin2018.v1.n2.p143-163

Almeida, Maria Antónia Pires. 2015. «Mulheres na política portuguesa.» In Percursos feministas: desafiar os tempos, editado por Eduarda Ferreira, Isabel Ventura, Luísa Rego, Manuela Tavares, Maria Antónia Pires de Almeida, 164-174. Lisboa: UMAR/Universidade Feminista.

Amin, Ângela. 2020. Parecer proferido em Plenário ao PL nº. 349, de 2015. Disponível no endereço https:/ / www.camara.leg.br/proposicoesWeb/prop_mostrarintegra;jsessionid=node0fh3p2ca55vqf1 wkgvy5ivv66626172081. node0?codteor=1949662\&filename=Tramitacao-PL+349/2015 [Consultado em 27 de junho de 2021].

Azevedo, Camyla Galeão de. 2019. «Mulheres na política e a divisão sexual do trabalho: retratos da sub-representação feminina na política do Estado do Pará.» Dissertação de Mestrado, Programa de Pós-Graduação em Direito, Políticas Públicas e Desenvolvimento Regional, Centro Universitário do Estado do Pará. Disponível no endereço https: / / www.cesupa.br/MestradoDireito/dissertacoes/2019/Dissertacao_Camyla_ Galeao.pdf [Consultado em 21 de maio de 2021].

Biroli, Flávia. 2010. «Gênero e família em uma sociedade justa: adesão e crítica à imparcialidade no debate contemporâneo sobre justiça.» Revista de Sociologia e Política 18(36): 51-65. DOI: https: / / doi.org/10.1590/S0104-44782010000200005

Dantas, Fernanda Argolo, Linda Oliveira Rubim. 2018. «"TCHAU QUERIDA!": Questões de gênero na cobertura da mídia sobre o governo Dilma.» Revista Observatório 4(1): 466-491. DOI: https: / / doi.org/10.20873/uft.2447-4266.2018v4n1p466 
A Federação. 1886. «Notícia sobre alistamento de Izabel Dillon.» A Federação (289). Partido Republicano. Disponível no endereço http:/ / memoria.bn.br/DocReader/DocReader.aspx?bib=388653\&pesq $=\% 22$ Izabel $\% 20 \%$ 20Dillon $\% 22 \&$ pasta $=$ ano $\%$ 20188\&pagfis $=3386$ [Consultado em 23 de junho de 2021].

Ferreira, Virgínia. 1999. «Os paradoxos da situação das mulheres em Portugal.» Revista Crítica de Ciências Sociais 52/53: 199-227. Disponível no endereço http:/ / hdl.handle. net / 10316/11571 [Consultado em 25 de maio de 2021].

Heller, Eva. 2014. A psicologia das cores. Como as cores afetam a emoção e a razão. Barcelona: Editora Gustavo Gili.

Instituto Update. 2020. Eleitas: mulheres na política. Disponível no endereço https:/ / www. institutoupdate.org.br / eleitas/ [Consultado em 12 de junho de 2021].

Jenkins, Henry. 2009. «Confronting the Challenges of Participatory Culture. Media Education for the 21st Century.» The John D. and Catherine T. MacArthur Foundation. Disponível no endereço https://www.macfound.org/media/article_pdfs/jenkins_white_ paper.pdf [Consultado em 22 de novembro de 2021].

Lauris, Élida, Maurício Hashizume. 2020. Violência Política e Eleitoral no Brasil: panorama das violações de direitos humanos de 2016 a 2020. Coordenado por Élida Lauris, Sandra Carvalho, Gláucia Marinho e Darci Frigo. Curitiba: Terra de Direitos e Justiça Global. Disponível no endereço http:/ / www.global.org.br/wp-content/uploads / 2020/09/ Relat\%C3\%B3rio_Violencia-Politica_FN.pdf [Consultado em 12 de junho de 2021].

Liguori, Maíra. 2015. «O machismo também mora nos detalhes.» Disponível no https: / / www.geledes.org.br/o-machismo-tambem-mora-nos-detalhes/ [Consultado em 22 de novembro de 2021].

Lousada, Isabel. [2011]. «Escrevendo e bordando, a nação e a bandeira, as palavras e os actos: símbolos e poder pela pena de Adelaide Cabete e Carolina Beatriz Ângelo.» In Anais do XIV Seminário Nacional Mulher e Literatura / V Seminário Internacional Mulher e Literatura. Disponível no endereço https: / / run.unl.pt/ bitstream/10362 / 6936/1/isabel_lousada.pdf [Consultado em 20 de março de 2021].

Lunz, Leandro da Silva (2021). «Mulheres na política: Myrthes Bevilácqua Carradi e Luzia Alves Toledo no poder legislativo - 1980 a 2018.» Revista do Arquivo Público do Estado do Espírito Santo 4(7): 83-96.

Lusa. 2021. «Portugal tem mais mulheres no Governo e Parlamento que média da UE». Público, Igualdade de Gênero. Disponível em https: / / www.publico.pt/2021 / 03 / 07 / politica/noticia/portugal-mulheres-governo-parlamento-media-ue-1953412 [Consultado em 27 de junho de 2021].

Ministério do Interior. 1890. «Sobre o alistamento.» A Ephoca, 18 de abril, p. 2. Disponível no endereço http:// memoria.bn.br/DocReader/DocReader.aspx?bib=373370\&pesq=\% 22isabel $\% 20$ souza $\% 20 \mathrm{de} \% 20$ mattos $\% 22 \&$ pasta $=$ ano $\% 20189 \&$ pagfis $=672$ [Consultado em 23 de junho de 2021].

Penaforte, Pandora Gonçalves de Porto Guimarães. 2017. «Opiniões "sem rosto": o comentário anónimo e construção da opinião pública.» Dissertação de mestrado, ISCTE-IUL. Disponível em http:/ / hdl.handle.net/10071/14848 [consultado em 20 de setembro de 2021].

Pinho, Tássia Rabelo de. 2020. «Debaixo do Tapete: A Violência Política de Gênero e o Silêncio do Conselho de Ética da Câmara dos Deputados.» Revista Estudos Feministas 28(2). DOI: https: / / doi.org/10.1590/1806-9584-2020v28n267271

Pinto, Céli Regina Jardim. 2010. «Feminismo, História e Poder.» Revista de Sociologia e Política 18(36): 15-23. Disponível em https: / / www.scielo.br/j/rsocp/a/GW9TMRsY gQNzxNjZNcSBf5r / ?lang=pt\&format=pdf [Consultado em 15 de junho de 2021 
Portugal. 1911. «Código Eleitoral» Disponível no endereço http://app.parlamento.pt/ upload / Comunicar / Anexos / 2015 / N10/ codigoeleltoralabr1911.pdf [Consultado em 23 de junho de 2021].

Portugal. 1913. «Código Eleitoral.» Disponível no endereço http:/ /app.parlamento.pt/ upload / Comunicar / Anexos / 2015/N10/ codigoeleitoral1913.pdf [Consultado em 23 de junho de 2021].

Recuero, Raquel. 2014. «A questão do ódio nos sites de rede social.» Disponível no http:/ / www.raquelrecuero.com/arquivos / 2014/10/a-questao-do-odio-nos-sites-de-redesocial.html [Consultado em 21 de março de 2021]

Ribeiro, Fábio Fonseca. 2013. «A participação dos cidadãos nos média portugueses: estímulos e constrangimentos.» Tese de Doutoramento em Ciências da Comunicação, Especialidade de Sociologia da Comunicação, Universidade do Minho. Disponível em http:// repositorium.sdum.uminho.pt/handle/1822/27212 [Consultado em 20 de setembro de 2021].

Saffioti, Heleieth. 2013. A mulher na sociedade de classes. São Paulo: Expressão Popular.

Santos, Maria Helena, Ana Espírito-Santo. 2017. «Para além dos Números: Transformações de Género associadas à Lei da Paridade.» Journal of Studies on Citizenship and Sustainability 2: 18-34.

Senado Federal. 2020. Violência afasta mulheres da política, dizem debatedoras. Disponível no endereço https: / / www12.senado.leg.br/noticias/materias/2020/03/05/violencia-afastamulheres-da-politica-dizem-debatedoras [Consultado em 23 de novembro de 2021].

Solnit, Rebecca. 2017. Os homens explicam tudo para mim. Trad. de Isa Mara Lando. São Paulo: Cultrix.

Tiburi, Márcia. 2019. Feminismo em comum: para todas, todes e todos. Rio de Janeiro: Rosa dos Tempos.

Toledo, Cláudia Masani Queda de, e Neymilson Carlos Jardim. 2019. «A baixa representatividade feminina na política: obstáculo a ser vencido na democracia brasileira.» Revista da Faculdade de Direito da Universidade Federal de Uberlândia, 47(2):318-333. Disponível em https: / / www.researchgate.net/publication/338613921_A_baixa_representatividade _feminina_na_politica [Consultado em 22 de novembro de 2021].

Camila Lamartine. Investigadora do Instituto de Comunicação da Nova (ICNOVA). Doutoranda em Ciências da Comunicação com especialização em Ciências Sociais pela Universidade Nova de Lisboa (UNL). Membro da Associação Portuguesa de Ciências da Comunicação (SOPCOM). Jornalista e Mestre em Branding and Design pela Universidade Europeia (IADE) e Universidade da Beira Interior (UBI). Tem publicado acerca dos feminismos, ciberespaço e novos ativismos sociais.

Camila Franco Henriques. Doutoranda na Faculdade de Direito da Universidade de Lisboa. Pesquisadora de Direitos Humanos, inclusão social e desigualdade de gênero. Advogada. Integrante da Comissão da Mulher Advogada - OAB/PA. Coordenadora do Grupo de Pesquisa Gênero e Justiça - perspectivas interdisciplinares. Integrante do Núcleo de História do Direito (FDUL). Mestre em Direitos Humanos e Inclusão Social pela UFPA, com período de estudos na PUC/PR e visiting scholar na American University Washington College of Law.

Artigo recebido a 1 de julho e aceite para publicação a 10 de outubro de 2021. 